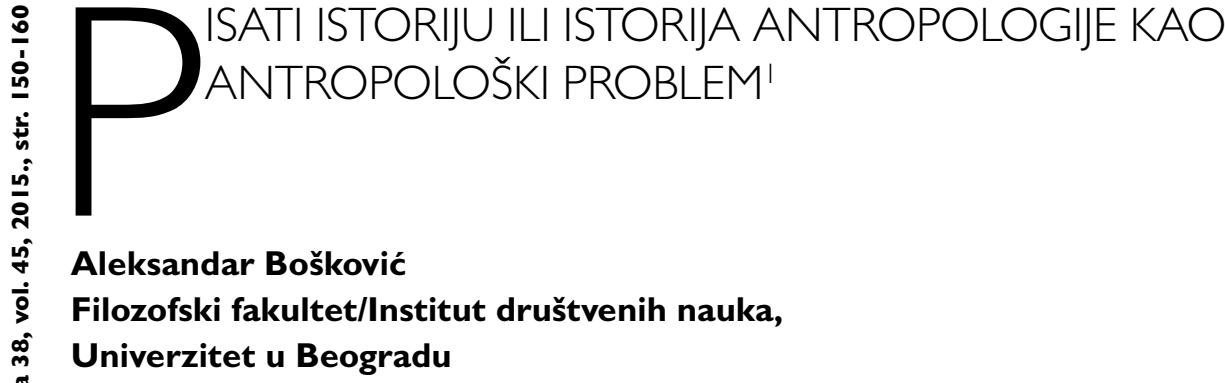

\begin{abstract}
Tekst se bavi problemima koje donose pisanje i objavljivanje istorija antropologije. Posebno se razmatra situacija sa objavljenim knjigama na ovu temu u delovima nekadašnje Jugoslavije - pre svega u Srbiji, Hrvatskoj i Sloveniji - kao i sa njihovom primenjivošću u kursevima na fakultetima gde se predaje istorija antropologije. Kao konkretna "studija slučaja" analizira se novo, dopunjeno izdanje Eriksenove i Nilsenove knjige (Eriksen i Nielsen 2013). Na kraju teksta autor pruža još nekoliko primera pisanja istorije antropologije, koji pokazuju kombinaciju praktičnih i političkih elemenata, kao i neke od rizika koje sa sobom nosi ova vrsta tekstova.
\end{abstract}

Ključne reči: istorija antropologije, politika antropologije, prevodi - antropologija, interpretacija u antropologiji

Činjenica da većina savremenih [antropoloških] pristupa ili aktivno odbacuje ili pasivno ignoriše, odnosno marginalizuje istoriju i kontekste koji su trajne prirode (bilo da su ovi konteksti evolucionistički bilo da su difuzionistički), snažno sugeriše da tu postoji neka skrivena evolucionistička shema: na kraju krajeva, postoje snažni pritisci da se određeni događaji i slučajevi povežu u jednu sveobuhvatnu hronologiju. Problem istorije je, dakle, povezan sa problemom evolucije, kao i sa opštim karakteristikama antropološkog diskursa. (Thomas 1996: 12)

\title{
Problem izvora
}

Istorija antropologije je područje istraživanja koje nikada nije bilo preterano popularno među antropolozima - pre svega zbog očiglednog naglaska na teoretskom aspektu, tj. pregledima i raspravama o različitim teoretskim perspektivama kroz koje je naša disciplina prolazila u skoro vek i po svog razvoja. ${ }^{2}$ Pošto je jedna od temeljnih karakteristika antropologije terensko istraživanje, sama ideja da se ono nekako može zaobići ili potisnuti u drugi plan (pa makar i samo zato da bi se izložilo ono što su drugi već o tome pisali) deluje malo sumnjivo - maltene kao kulturne studije, književna kritika (ove dve oblasti se, uz takozvane "postkolonijalne studije”, u antropološkoj imaginaciji najčešće pojavljuju kao "dežurni krivci”) ili kao neka slična disciplina koja bi htela od antropologije "uzeti" sve zanimljivo i egzotično, ali (ako je ikako

${ }^{1}$ Autor ovog teksta je u vreme njegovog pisanja bio angažovan na projektu "Društvene transformacije u procesu evropskih integracija - multidisciplinarni pristup” (III 47010), koji finansira Ministarstvo prosvete i nauke Republike Srbije. Tekst je napisan za vreme boravka na Max-Planck-Institut für ethnologische Forschung u Halleu, uz podršku stipendije DAAD SR Nemačke. Za nabavljanje knjige A History of Anthropology, autor je veoma zahvalan dr Željki Buturović (Institut društvenih nauka, Beograd), a za tekst "Na encruzilhada portuguesa" Joãou de Pina-Cabralu (University of Kent). Stavovi i opservacije izneseni u tekstu ni na koji način ne odražavaju stavove koje zastupaju DAAD, Max-Planck-Institut für ethnologische Forschung, dr Buturović ili prof. Pina-Cabral.

${ }^{2}$ Postoji više načina da se odredi simboličan ili stvarni početak antropologije kao naučne discipline. Za potrebe ovog teksta kao ključnu godinu uzimam 1871, kada je Tylor objavio svoju dvotomnu studiju Primitive Culture. Zbog toga se neću baviti tekstovima koji u značajnoj meri zahvataju period pre Tylora (antiku, srednji vek, prosvetiteljstvo itd.), bez obzira na nesporan uticaj koji su neki od autora (pre svega krajem XVIII i u prvim decenijama XIX veka) imali na razvoj antropologije. 
moguće) bez mnogo truda. Naravno, u praksi su dobre istorije antropologije uglavnom pisali autori koji su se već pokazali i dokazali kao vrsni istraživači. Na primer, šta god kritičari mislili o njegovim teorijskim stavovima, norveškom antropologu Thomasu Hyllandu Eriksenu (koautoru jedne od najnovijih knjiga koja se bavi istorijom i teorijom antropologije - Eriksen i Nielsen 2013) se ne može odreći impresivno iskustvo rada na terenu, i to u vrlo različitim situacijama i delovima sveta (Mauricijus, Trinidad, Norveška, Australija). Čak i kada se o ranim antropolozima (npr. o Sir E. B. Tyloru i Sir J. G. Frazeru) ponekad govori podsmešljivo, kao o ljudima koji su se antropologijom bavili "iz fotelje" (engl. armchair anthropologists), a ne "pravim" "ili "herojskom" terenskim istraživanjem (poput npr. njihovih savremenika Williama Robertsona Smitha ili Lewisa Henryja Morgana), ova karakterizacija ne uzima u obzir činjenicu da su oni (baš kao i mnogi njihovi savremenici) svoje ključne radove pisali pre svega na osnovu opservacija, zapisa, svedočanstava i pisama drugih ljudi, najčešće putnika ili misionara koji su dugo vremena bili "na terenu". ${ }^{3}$ Prilikom pisanja istorije antropologije važe određeni parametri koji su i inače prisutni tokom rada na bilo kakvim istorijama. Ovo se pre svega odnosi na izvore na osnovu kojih pisane istorije nastaju - pa tako možemo razlikovati primarne i sekundarne izvore.

Kada se radi o primarnim izvorima, to su beleške sa terena (najčešće u vidu pisama), dnevnici i raznovrsna etnoistorijska građa, koja se često nalazi u arhivima ili specijalnim kolekcijama u muzejima. Primer ovakvih kolekcija je zaostavština E. E. Evans-Pritcharda, koja se čuva u 14 kutija u Pitt-Rivers muzeju u Oxfordu. Primer studije nastale na osnovu arhivske građe jeste Cliffordova knjiga inspirisana životom i radom (prvo na Novoj Kaledoniji od 1902. do 1926. godine, a kasnije u Parizu) francuskog etnologa i misionara Mauricea Leenhardta (Clifford 1982). Cliffordova knjiga predstavlja i zanimljiv primer uspešnog interdisciplinarnog pristupa - njegov doktorat (iz koga je ova odlična knjiga nastala) bio je iz područja istorije, ali je njegova studija odmah prihvaćena kao jedan od ključnih tekstova iz istorije antropologije. S druge strane, upotreba nekih primarnih izvora može ponekad biti problematična, posebno kada se radi o beleškama za koje se nikada nije smatralo da će biti objavljene - primer za ovo su famozni dnevnici Bronislawa Malinowskog, čije je (neplanirano) objavljivanje 1967. izazvalo priličnu konsternaciju među antropolozima (upor. poglavlje "I Witnessing: Malinowski’s Children” u Geertz 1988). ${ }^{4}$ Među primarne izvore spadaju, naravno, i lična svedočanstva, koja mogu biti snimljena ili, u novije vreme, sačuvana u digitalnom formatu. U poslednjih nekoliko decenija je britanski antropolog Alan Macfarlane snimio velik broj razgovora sa vodećim antropolozima. Ti razgovori su dostupni u pisanom obliku i kao video zapisi, zbog čega predstavljaju izvanrednu građu za proučavanje istorije antropologije.

Naravno, kad se radi o ličnim svedočanstvima i intervjuima, ponekad nije lako proceniti pouzdanost određenih iskaza, posebno kada se radi o razgovorima koji se vode u sklopu terenskih istraživanja. Tako je svojevremeno francuski etnolog Marcel Griaule (1948) na osnovu svojih razgovora sa svojim "ključnim informantom” među Dogonima iz Malija došao do niza fantastičnih zaključaka, uključujući i to da su pripadnici ovog zapadnoafričkog naroda znali za postojanje zvezde Sirius (koja se inače ne može videti golim okom) i još puno sličnih stvari koje su kasniji istraživači osporili. Južnoafrički antropolog W. D. Hammond-Tooke mi

\footnotetext{
${ }^{3}$ Ovu distinkciju je, bez vrednosnih sudova, prvi upotrebio A. C. Haddon, u verovatno prvoj objavljenoj istoriji antropologije (Haddon 1910).

${ }^{4}$ Clifford Geertz je objavio prilično oštru kritiku izdanja Dnevnika u New York Review of Books 9 (4), u broju od 14. septembra 1967. Kritike njegove recenzije su objavljene u narednom broju, od 9. novembra, kao dva pisma od strane nekadašnjih Malinowskijevih studenata - Hortense Powdermaker i Ashleyja Montagua. Cela prepiska je dostupna na: http://lemetro5.blogspot. de/2005/08/under-mosquito-net.html
} 
je svojevremeno ${ }^{5}$ rekao da smatra da bi sve studije afričkih "tradicionalnih religija” objavljene do početka 1970-ih trebalo jednostavno ignorisati. Hammond-Tooke (inače autor više desetina tekstova i nekoliko knjiga o afričkim religijama, kao i jedan od najzaslužnijih autora za prodor strukturalističkog metoda u anglofonu antropologiju) je, naime, smatrao da gotovo sve monografije objavljene do početka 1970-ih imaju ozbiljne nedostatke - pre svega metodološke. U svim slučajevima, govorio je, ove knjige su bile zasnovane na sledećem scenariju: istraživač (belac, Evropljanin, kao što je to na primer bio Griaule) dolazi u neko "izolovano" afričko pleme (poput Dogona u Maliju). Među članovima plemena u koje je došao odmah uspostavlja kontakt sa lokalnim filozofom koji konačno ima nekoga ko će ga saslušati (Ogotommêli u slučaju Griaulea i Dogona). Neko ko je čitavog svog života bio kulturno i socijalno izolovan, jer ljude sa kojima je živeo njegovi uvidi jednostavno nisu zanimali, konačno dobiva pažljivog sagovornika - stranca, obrazovanog zapadnjaka koji je došao izdaleka, koji će razumeti svu dubinu i značaj njegovih saznanja... Tako su čitave monografije zasnovane na mišljenjima i stavovima jedne jedine osobe (lokalnog filozofa) - koji se onda projektuju kao stavovi ili "tradicije” čitave zajednice. Kasnije su čitave generacije studenata obrazovane na ovakvim “životnim pričama” transformisanim u kolektivne istorije i kolektivna sećanja.

Ova situacija upućuje i na potrebu razumevanja distance koja uvek postoji između posmatrača i posmatranih. Ona se ne može izbrisati niti "dekonstruisati”, ali bi bilo dobro da naše koleginice i kolege budu svesni njenog postojanja i značaja. Zato je zanimljivo da je Claude Lévi-Strauss na više mesta pominjao analogiju između antropologije (izraz koji je on upotrebljavao je etnologija) i astronomije. Astronomija kao svoj predmet konstruiše nešto što je daleko, ali ta daljina ne predstavlja ograničenje, već je konstitutivni faktor nastanka jedne nauke - jednako kao i u slučaju kad se radi o daljini koja postoji između antropologa i onih koje antropologinje i antropolozi proučavaju (Hénaff (2000) razvija ovu ideju u prvom poglavlju svoje knjige).

Među sekundarne izvore spadaju etnografije, odnosno monografije koje su proizvod terenskih istraživanja. Većina istorija antropologije je nastala baš na osnovu sekundarnih izvora, a njihov izbor često govori i o preferencama autora, pre svega u smislu teorija koje se odlučuju da naglase (ili zapostave) u svojim knjigama. Takođe, upotreba određenih izvora zavisi i od toga da li autori žele da "trasiraju" određenu genealogiju koja vodi do jedne osobe (kao na primer do Adolfa Bastiana u nemačkoj tradiciji - kao što to čini Köpping 2005) ili koriste određeni ključni događaj da u odnosu na njega posmatraju razvoj etnologije i antropologije (kao što je to bio Prvi svetski rat, v. Johler, Marchetti i Scheer 2010), ili ih, pak, pre svega zanima razvoj teorije i metodologije u specifičnom društvenom kontekstu (na primer, Kraus 2004; Oberdiek 2013). Još jedan primer upotrebe sekundarnih izvora jeste njihovo navođenje samo zbog toga da bi njihovi autori bili kritikovani - strategija koju je u svom sveobuhvatnom pregledu istorije brazilske etnologije ${ }^{6}$ vrlo uspešno upotrebio brazilski antropolog Eduardo Viveiros de Castro da bi praktično ismejao stavove svoje koleginice Alcide Ramos, pokazujući da je ona neke svoje navodno originalne ideje u stvari "pozajmila” od Lévi-Straussa (1999: 126-127).

\footnotetext{
${ }^{5}$ Tokom razgovora u njegovoj kući u predgrađu Johannesburga, 2002.

${ }^{6}$ Izraz etnologia indígena se u brazilskoj akademskoj terminologiji koristi za označavanje proučavanja kultura (brazilskih) Indijanaca.
} 


\section{Politika objavljivanja istorije antropologije}

Različiti autori su prišući svoje istorije ovoj temi pristupali sa različitim nivoima generalizacije. Tako Alfred Court Haddon, prvi predavač socijalne antropologije na Univerzitetu u Cambridgeu, u svojoj knjizi (Haddon 1910) predstavlja jednu opštu istoriju antropologije. On počinje od etimologije reči i pojma, nastavljajući svoj pregled preko fizičke antropologije (deo knjige koji se kod njega zove Human Biology) i kulturne antropologije, koja u njegovom pregledu discipline uključuje i lingvistiku (Cultural Anthropology, or Ethnology), pa sve do sociologije (Comparative Sociology), u čijem okviru Haddon daje i pregled proučavanja religije i mitova. Koliko mi je poznato, on je jedini autor koji sociologiju smatra delom antropologije - pre svega zato što je verovao da se sociologija bavi konkretnijim stvarima, dok antropologija poseduje jedan viši nivo generalizacije. ${ }^{7}$ Kada se radi o uključivanju rasprava o biološkoj antropologiji, Penniman (nekadašnji kurator Pitt-Riversovog muzeja) ih u knjizi završenoj 1935. - tačno sto godina pošto je Charles Darwin posetio ostrva Galapagos hronološki uključuje u određena poglavlja. Tako on razmatra arheologiju i paleontologiju u periodu između 1859. i 1900. godine (Penniman 1965: 159-177), zatim fizičku antropologiju i psihologiju u periodu između 1900. i 1935. godine (1965: 182-219), dok je u delu knjige koji je naknadno dodat posle Drugog svetskog rata jedan od "novih" autora napisao kratko poglavlje o razvoju fizičke antropologije posle 1935. godine (1965: 285-319). Pokušaj jedne sveobuhvatne istorije kakve danas srećemo prvi je kroz svoju sintezu par godina posle njega izveo američki antropolog Robert Harry Lowie (u to vreme profesor na University of California at Berkeley), koji je pišući o onome što je nazvao etnološkom teorijom nastojao da smesti antropologiju u odnosu na druge naučne discipline (pre svega pravo, istoriju, geografiju i psihologiju). Lowie predstavlja razvoj teorija od početka 19. veka (sa posebnim akcentom na nemačke autore), stavljajući u fokus svog istraživanja, prema njegovim rečima, "onaj deo antropologije (kako se taj pojam shvata na engleskom govornom području) koji se bavi kulturom. Unutar te sfere [ova knjiga] pokušava da ukaže na pravac teorijskog progresa, ali pošto se teorija mora oslanjati na činjenice, posebno se razmatra rast znanja kroz usavršavanje tehnika za prikupljanje informacija” (Lowie 1937: vii).

Konačno, verovatno najdetaljniji primer predstavljanja jedne opšte istorije antropologije daje nemački antropolog i publicista Petermann, saradnik Instituta za etnologiju LudwigMaximilians-Universitäta u Münchenu. On više od polovine knjige koja broji preko 1000 stranica posvećuje aspektima biološke antropologije i arheologije (Petermann 2004) - mada se u poslednjih nekoliko decenija izraz koji on koristi (Ethnologie) sa nemačkog prevodi kao socijalna antropologija (engl. social anthropology). Ovo je s jedne strane Petermannov lični protest zbog neslaganja sa evolucijom upotrebe ovog koncepta u nemačkom jeziku, za koji smatra da je sada postao nepotrebno ograničavajući. Sa druge strane, radi se o autoru koji je imao relativno atipično obrazovanje za jednog nemačkog antropologa (završio je filologiju i egiptologiju), ali koji je vrlo snalažljiv u promociji svog rada - tako je tekst svoje knjige prethodno objavljivao kao feljton u vodećim nemačkim dnevnim novinama Frankfurter Allgemaine Zeitung. U svakom slučaju, radi se o zanimljivom pokušaju kontinuiteta sa nekadašnjom idejom antropologije kao veoma opšte "nauke o čoveku" (Haddon 1910: 2; Penniman 1965: 15). ${ }^{8}$ Drugačiji - i savremenim kretanjima u antropologiji daleko primereniji - pristup na

\footnotetext{
${ }^{7}$ Ovo je relativno zabavno posmatrati iz savremene perspektive, gde antropolozi (npr. u Britaniji) smatraju da ih sociolozi ugrožavaju.

${ }^{8}$ Sa druge strane, Marett definiše antropologiju kao "celokupnu istoriju čoveka, onako kako ga je oblikovala evolucija" (1912: 7), odnosno kao "Darwinovo dete" (1912: 8). Meni je nešto bliže Handlerovo određenje da je antropologija posvećena proučavanju
} 
nemačkom jeziku ima Hahn (2013), koji kombinuje pregled najvažnijih teorija sa njihovim najistaknutijim predstavnicima. Hahn takođe posebno daje i pregled različitih regionalnih tradicija (američke, britanske, francuske i nemačke) - slično kao i Bošković (2010).

Razmatranje teorija iz fizičke antropologije, ili barem pominjanje Darwina, prisutno je i u nekoliko prevoda autora sa francuskog govornog područja objavljenih u Srbiji tokom poslednjih petnaest godina (Poarije 1999; Delijež 2012). S obzirom na to da se radi o autorima iz frankofonskih zemalja (jedan je iz Francuske, a drugi iz Belgije), gde se antropologija predaje na vrlo drugačiji način nego na prostorima nekadašnje Jugoslavije, praktičan učinak koji ovi tekstovi imaju na studente je relativno ograničen, iako predavači često insistiraju na njihovom čitanju. ${ }^{9}$ Pretpostavljam da se radi o tome da je izdavaču ovih knjiga, dr Ivanu Čoloviću, francusko govorno područje (i frankofonska perspektiva) jednostavno bliža i razumljivija. U biblioteci "XX vek", u kojoj je Deliègeova knjiga izašla, pre više decenija je objavljen dvotomni prikaz i nekih (pre svega američkih) teoretičara kulture, i to iz perspektive kulturnog materijalizma (Hač 1979). U poređenju sa njegovim frankofonskim kolegama, Hatchov tekst je daleko razumljiviji, mada je njegova knjiga odavno rasprodata, a njegovi teorijski pogledi su beznadežno zastareli - jer se u međuvremenu dogodio kraj kolonijalizma, početak antropologije odnosa među polovima, interpretativni zaokret u antropologiji, "pisanje kultura" i još ponešto. ${ }^{10}$ Nešto je umereniji i malo manje ambiciozan u zahvatanju vrlo različitih teorija američki antropolog koji predaje na Univerzitetu u Edinburghu, Alan Barnard (2011) - mada njegova obimna knjiga ipak zahteva određeno predznanje. ${ }^{11} \mathrm{Na}$ primer, da krenem od početka, kada Barnard raspravlja o razlici između pojmova "antropologija" i "etnologija" (Barnard 2000: 1-2), za nekoga ko studira u Beogradu ovo može biti malo konfuzno - posebno s obzirom na to da su rasprave na ovu temu u okviru etnologije i antropologije u Srbiji odavno završene. Pored toga, iako je Barnardov pristup izlaganju teorija sveobuhvatan, on je pomalo anglocentričan. Njegovo upućivanje na druge tekstove (za dodatno čitanje) pokazuje autorovo izuzetno poznavanje materije, ali je relativno beskorisno u sredinama kao što su Hrvatska ili Srbija, gde knjige na koje on upućuje ne samo što većinom nisu prevedene, nego ih nema ni u bibliotekama. S druge strane, Boškovićeva knjiga koju je godinu dana ranije objavio isti izdavač, zagrebački Jesenski i Turk, ne zahteva predznanje, a kombinuje sinhronički i dijahronički pristup u izlaganju različitih teorija (Bošković 2010). Kao i Barnard, Bošković kombinuje beleške sa predavanja iz različitih sociokulturnih i geografskih konteksta, s obzirom da je predavao na univerzitetima u Velikoj Britaniji, Sloveniji, Brazilu i Južnoj Africi. ${ }^{12}$ Takođe, reč je o autoru koji je već dosta objavljivao kada se radi o proučavanju drugih (Eriksen upotrebljava izraz "marginalnih") antropoloških tradicija koje su izvan tradicionalnih "centara” antropološke produkcije. To je uočljivo i iz nekoliko priređenih knjiga

\footnotetext{
"značajnih drugih" (engl. significant others - 2004: 3). O terminološkim nedoumicama u istorijskoj perspektivi takođe Bošković (2005: 12-13) i Bošković (2014: 27-33).

${ }^{9}$ Ova opservacija je rezultat reakcija studenata druge godine studija, kojima od 2010. predajem Antropološke i etnološke teorije na Filozofskom fakultetu u Beogradu, a koji uglavnom tvrde da je iz knjiga francuskih autora veoma teško razumeti ključne antropološke koncepte.

${ }^{10}$ Kovačević (2008) je u pravu kada tvrdi da ne treba precenjivati značaj ovog pravca, što sam i sâm pominjao na više mesta (Bošković 2010, 2014). Diskusije koje su otvorene kao posledica Geertzove verzije interpretativne antropologije i preispitivanja dometa relativizma su bile daleko uticajnije, barem kada se radi o severnoameričkoj antropologiji.

${ }^{11}$ Barnard, vrhunski autoritet za San/ Bušmane iz Namibije i Južne Afrike, sjajno je iskoristio činjenicu da je jedno vreme bio urednik izdanja za antropologiji u izdavačkoj kući Cambridge University Press, što je svakako pomoglo objavljivanje njegove - inače odlične - knjige. Takođe, Barnard je napisao ovu knjigu i da bi mu, između ostalog, koristila na njegovim predavanjima u Edinburghu. Zbog toga je knjiga uklopljena u određeni sistem. Za razliku od njegovih studenata, naši studenti (u Hrvatskoj, Srbiji itd.) određene koncepte ne rade u isto vreme, niti na istim godinama studija kao njihovi kolege u Škotskoj i Velikoj Britaniji. Zbog toganailaze na izraze i pojmove koji su im potpuno nepoznati i neprilagođeni tekstu koji se na ovom području koristi kao uvodni tekst.

${ }^{12}$ Zahvaljujući angažovanju kolega sa Filozofskog fakulteta, od 2009. predaje na Odeljenju za etnologiju i antropologiju u Beogradu.
} 
(Bošković 2008; Bošković i Hann 2013) koje, doduše, ostaju relativno nepoznate ovdašnjoj javnosti. Zanimljivo je da je knjiga Kratak uvod u antropologiju prethodno objavljena i u Srbiji 2010. godine, u izdanju beogradskog Službenog glasnika, te je do početka 2012. to izdanje rasprodato.

Određeni problem predstavlja i zakašnjenje sa kojim se u regionu objavljuju knjige stranih autora. Barnardova knjiga predstavlja izuzetak, ali Hatch i Poirier su objavljeni sa određenim vremenskim zaostatkom. Pa ipak, verovatno su najgore prošli studenti u Sloveniji, gde je 1998. izašla Kuperova istorija britanske antropologije, koju je on u međuvremenu više puta prerađivao, dopunjavao i menjao. Treće izdanje njegove knjige, u kojem je već bio promenjen i dopunjen značajan deo teksta, objavljeno je 1999. godine (slovenački prevod je prevod drugog izdanja, koji je ponovno objavljen 2005), a četvrto i (za sada) konačno izdanje izašlo je 2014. godine. Čitava ideja da se ideje stranih autora moraju prevoditi i objavljivati po redosledu kako su oni svoje tekstove prvi (ili drugi) put objavljivali - makar i po cenu da su ti autori u međuvremenu značajno dopunili (a ponekad i promenili) svoje stavove - čitaoce i javnost na ovim prostorima stavlja u situaciju strele iz Zenonove aporije, koja nikada neće doći do svog cilja. Pretpostavljam da bi bilo daleko svrsishodnije imati neki plan i program (odnosno ideju šta se želi postići) prevođenja i objavljivanja ključnih antropoloških tekstova, koji bi se onda mogao realizovati u saradnji sa onima koji predaju na osnovu tih tekstova - bilo da rade u Sloveniji, Hrvatskoj ili Srbiji. Uveren sam da bi autori i autorke knjiga koje bi se prevodile bili vrlo raspoloženi da aktivno pomognu u realizaciji jedne ovakve ideje. ${ }^{13}$

Važan deo razmatranja istorija antropologije predstavljaju i pregledi razvoja određenih regionalnih tradicija, poput već pomenutog Kuperovog (Kohl 1987; Hammond-Tooke 1997; Viveiros de Castro 1999; Ntarangwi, Mills i Babiker 2006; Viegas e Pina-Cabral 2014). Tako Ivan Kovačević, redovni profesor na Odeljenju za etnologiju i antropologiju beogradskog Filozofskog fakulteta, u svojim tekstovima $(2006,2014)$ daje veoma sažet i jasan pregled razvoja etnologije/antropologije u Srbiji u poslednjih tridesetak godina. Na drugom mestu (2008), kada piše o novijoj istoriji antropologije, on kritički razmatra ono što smatra za nekritičko prihvatanje "postmodernističkih" tokova iz savremene antropologije (pre svega vezano za pravac oko "pisanja kultura"), takođe u kontekstu razvoja discipline u Srbiji. Nažalost, kao i u slučaju Kuperovih tekstova o britanskoj antropologiji, Kovačević ne pominje dovoljno sopstveni uticaj na značajne promene koje su se dogodile u srpskoj etnološkoj i antropološkoj tradiciji u poslednjih nekoliko decenija - osim vrlo stidljivo (Kovačević 2014: 26). ${ }^{14}$

\section{Istorija antropologije kao studija slučaja}

Nedavno je objavljeno drugo, značajno prerađeno izdanje knjige A History of Anthropology Tomasa H. Eriksena i njegovog danskog kolege Finna Sieverta Nielsena. Knjiga je prvi put objavljena 2001. u izdavačkoj kući u kojoj je Eriksen jedan od urednika. Ona je svojom jasnoćom (koja je inače karakteristična za Eriksenov stil pisanja) odmah stekla mnogobrojne poklonike, a našla je i mesto na spisku obavezne literature za predmet Uvod u etnologiju i antropologiju na Filozofskom fakultetu u Beogradu.

\footnotetext{
${ }^{13}$ Svojevremeno me je izdavač Geertzovog Tumačenja kultura zamolio da posredujem oko dobijanja prava za prevođenje ove knjige po nešto nižoj ceni s obzirom na to da je znao da poznajem autora. Naravno, Geertz se odmah odazvao molbi i problem je brzo rešen.

${ }^{14}$ Svoje mišljenje o kvalitetu rada na ovom Odeljenju već sam izložio na drugom mestu (Bošković 2014: 10) i nema razloga da ga ovde ponavljam.
} 
Knjiga je $\mathrm{u}$ odnosu na prvo izdanje proširena sa više od dvadeset strana novog teksta. Neke nepreciznosti iz prvog izdanja su ispravljene (kao to da je Rivers predavao u Cambridgeu, a ne u Oxfordu, 2013: 34), neke su ponovo tu (vojska posle državnog udara dolazi na vlast u Brazilu 1964, a ne 1963, 2013: 198), a učinjen je i određen napor da se u nešto većoj meri predstave "druge antropologije" (pre svega kroz reference na Bošković 2008, kao i na autore iz različitih zemalja, od Danske do Kenije). Nešto veći prostor nego u prvom izdanju posvećen je misiji Dakar-Djibouti (1931-1933), jednom od ključnih događaja u istoriji francuske etnologije i antropologije. Nažalost, u knjizi se ponovo ne pominjanje uticaj koji je Michel Leiris imao na američke antropologe i čitav pravac oko "pisanja kultura" tokom 1980ih, a o čemu je dosta pisao James Clifford. Kao i u prvom izdanju, ova knjiga je podeljena na devet osnovnih poglavlja. Razlika je u tome što je nekoliko naslova malo promenjeno, pa se prvo poglavlje sada zove "Proto-antropologija" (Proto-Anthropology), dok se deveto zove "Globalne mreže" (Global Networks). ${ }^{15}$

U odnosu na neke druge preglede istorije antropologije (Bošković 2010), u knjizi je malo manje pažnje posvećeno starim Grcima i Rimljanima (i antičkom svetu uopšte), a nešto više prosvetiteljima i romantičarima (kao što čini i Barnard 2000, 2011). Knjiga kombinuje rasprave o teorijama i kontekstima u kojima su one nastajale sa ključnim ličnostima u antropologiji - opet u različitoj meri od druge dve spomenute, gde Barnard više insistira na teorijama (uostalom "teorija" se nalazi i u naslovu njegove knjige), ${ }^{16}$ a Bošković na ličnostima. ${ }^{17}$ Ono što posebno izdvaja Eriksenovu i Nielsenovu Istoriju jeste sociopolitički kontekst - razvoj antropologije je neodvojiv od konkretnih istorijskih okolnosti i društvenih i tehnoloških promena u svetu, od napretka u nauci, medicinskih otkrića koja su uticala na poboljšanje i produžavanje života populacija, preko posledica ratova i kolonijalnih osvajanja, pa sve do dekolonizacije i pojave dekonstruktivističkih pravaca. Oni insistiraju na predstavljanju i interpretaciji promenjenih političkih, demografskih i ekonomskih uslova, kao i uticaja koje su ove izmenjene okolnosti imale na razvoj društvenih nauka i procese razumevanja globalizovanog sveta koji se konstantno menja. Kao slikar koji slika širokim potezima četkice, Eriksen i Nielsen nastoje da sve ključne antropološke događaje smeste unutar specifičnih društvenih i istorijskih okolnosti, što njihov tekst čini i nekom vrstom društvene istorije. $\mathrm{Na}$ primer, insistiranje nekih američkih antropologa na interpretacijama mesta i uloge simbola u svakodnevnom životu mnogo je lakše razumeti ako se razume kontekst iz koga oni dolaze (američko društvo opterećeno nasleđem međurasnih odnosa, kompleksom krivice zbog tretmana američkih Indijanaca itd.).

Posebno je zanimljiva pažnja koju Eriksen i Nielsen posvećuju Karlu Marxu i njegovim uticajima. Na primer, "Manchesterska škola” (jedva pomenuta u Bošković 2010) je zaslužila značajan deo jednog poglavlja (Eriksen i Nielsen 2013: 107-112). Mada je još Max Weber u svojoj Protestantskoj etici iz 1905. pokazao da je protestantizam kao ideologija uticao na formiranje kapitalizma, a ne obrnuto (2013: 42), ${ }^{18} \mathrm{i}$ mada je upotreba marksizma u teoriji i praksi socijalističkih država (pre svega SSSR-a, njegovih satelita, ali i drugde) pokazala svo siromaštvo ovog sistema, marksistički pristupi su, posebno od 1960-ih, postali veoma popularni u antropologiji. Procesi dekolonizacije, pojava pravaca koji su kasnije nazvani "femini-

\footnotetext{
${ }^{15}$ U prvom izdanju knjige naslov prvog poglavlja je "Počeci" (Beginnings), a poslednjeg "Rekonstrukcije" (Reconstructions) Eriksen i Nielsen (2001).

${ }^{16}$ Mada zato Barnard u prvom Dodatku (Appendix 1) daje pregled svih ličnosti koje pominje u knjizi, zajedno sa godinama rođenja i smrti. Bošković ima Indeks (odnosno Registar) imena u srpskom izdanju knjige, dok su u hrvatskom izdanju indeksi spojeni.

${ }^{17}$ Lowie (1937) i Hahn (2013) takođe pominju određene ključne ličnosti, ali njihove knjige nisu u tolikoj meri određene pojedinačnim ličnostima i njihovim životima u istoriji antropologije.

${ }^{18}$ To bi inače bilo u skladu sa Marxovom "klasičnom” teorijom, prema kojoj su načini proizvodnje formirali "društvenu svest”, odnosno ideologiju.
} 
stičkom antropologijom”, reartikulacije strukturalizma (pre svega u Francuskoj), kao i opšte preispitivanje mesta i uloge autoriteta - sve to je učinilo da marksistički pristupi postanu "moderni” krajem 1960-ih i početkom 1970-ih. Naravno, kako kažu autori, nekoliko antropologa iz prethodne generacije - Julian Steward, Leslie White i Max Gluckman - bili su pod uticajem Marxa. Kako navode Eriksen i Nielsen: "Steward u svom materijalizmu, White u tehnološkom determinizmu, Gluckman kroz svoje interesovanje za krizu i konflikt. Međutim, referenci na Marxa u njihovom radu praktično nema" (2013: 139). U generacijama posle 1960, pre svega inspirisanim "strukturalnim marksizmom", ali i "teorijom sistema” (world systems theory), autori poput Mauricea Godeliera, Marvina Harrisa, Erica Wolfa ili Marshalla Sahlinsa razvijaju različite pristupe kojima pokušavaju da objasne promene u svetu. Kako pišu Eriksen i Nielsen, "Fundamentalni problem sa marksizmom u antropologiji je bio, i ostao, [to] da on u suštini predstavlja teoriju kapitalizma, i da je [marksističko] objašnjenje 'pre-kapitalističkih društava' zasnovano na spekulacijama i neadekvatnim podacima” (2013: 144). Pominjući autore jednog preglednog teksta iz 1980, koji su tvrdili da je "još rano da se 'pruži definitivna kritika' ovog pravca [marksizma]", Eriksen i Nielsen tvrde da je, izgleda, "ovaj pravac nekako iščezao za vreme dok je ovaj tekst bio u štampi” (2013: 144-145).

Mada ima isti naslov, osmo poglavlje knjige "Kraj modernizma?" (The End of Moderni$s m$ ?) je značajno revidirano u odnosu na izdanje iz 2001. U novom izdanju se nešto manje pominju "postkolonijalne studije", a daleko veći prostor se posvećuje recepciji "postmodernizma” (kako autori navode, od savremenih pregleda antropoloških teorija, Barnard [2000, 2011] ovom pravcu posvećuje dosta prostora - ali je dovoljno obazriv da ne da ocenu njegovog ukupnog značaja i uticaja). Više pažnje je posvećeno i autorima kao što su Dame Marilyn Strathern - koja je, doduše, pomenuta i u prvom izdanju (2001: 151), ali je njen rad sada jasnije povezan sa globalnim razvojem antropologije (2013: 185-186) - ili Tim Ingold i njegovo oslanjanje na biologiju i ekologiju. ${ }^{19}$ Naravno, autori ponovo značajnu pažnju posvećuju pravcu nastalom posle simpozijuma (i istoimene knjige) Writing Culture, ali više ne pominju i Geertzovu kritiku (tadašnje) mlađe generacije antropologa zbog "epistemološke hipohondrije" (Eriksen i Nielsen 2001: 148).

Konačno, deveto poglavlje novog izdanja ove Istorije antropologije, sada sa naglaskom na procese globalizacije (jedna od Eriksenovih omiljenih tema istraživanja tokom poslednje decenije), predstavlja pravo osveženje i još jedan vredan doprinos razumevanju savremenih pravaca. Nažalost, možda zbog relativno ograničenog prostora kojim su raspolagali, ili zbog konceptualnog okvira koji su sami sebi odredili, ${ }^{20}$ autori ostaju usredsređeni pre svega na takozvane "velike" tradicije (angloameričku, francusku i nešto manje nemačku), dok se ogromno bogatstvo i raznovrsnost drugih tradicija pominje maltene samo uzgred, uz nekoliko strana komentara o brazilskoj i ruskoj antropologiji, kao i uzgredno pominjanje Indije, Letonije, Srbije, Kolumbije, švedske etnologije, poljskog nadrealizma, litvanske semiotike, slovačkog strukturalizma i slovenačke Volkskunde (Eriksen i Nielsen 2013: 195-199). Ovo je verovatno propuštena šansa s obzirom na to da oba autora imaju određeno iskustvo u proučavanju drugih antropoloških tradicija, a Eriksen je bio ključna osoba u realizaciji panela iz koga je nastala knjiga o "drugim antropologijama", održanog na konferenciji EASA u Beču, septembra 2004, kao i koautor Uvodnog poglavlja u toj knjizi (Bošković 2008). ${ }^{21}$

\footnotetext{
${ }^{19} \mathrm{U}$ poslednjih petnestak godina Ingold je uticao na razvoj jednog sveobuhvatnog pristupa antropologiji na univerzitetu u Aberdeenu, sa posebnim akcentom na proučavanje "severnih naroda".

${ }^{20}$ I pored cilja koji su sami sebi postavili - Eriksen i Nielsen (2013: ix).

${ }^{21}$ Ovo poglavlje je preštampano u nedavno objavljenoj antologiji tekstova iz istorije antropoloških teorija (Erickson i Murphy 2013: 562-573).
} 
Naravno, svaka istorija predstavlja pre svega autorski tekst svojih tvoraca. Eriksen i Nielsen u Predgovoru insistiraju na tome da je ova njihova knjiga "nepretenciozna", a sam njen naslov (A History) implicira da se radi samo o jednoj, nikako jedinoj mogućoj niti definitivnoj, istoriji antropologije. Pored toga, razumno je pretpostaviti da će ova jasno napisana i relativno kratka knjiga biti čitana i korišćena kao vrlo upotrebljiv tekst za proučavanje razvoja naše discipline - posebno s obzirom na to da, iako je - kao što su autori napisali pre više od deset godina - "razvoj od ranog industrijskog i kolonijalnog doba do informatičkog doba globalnih modernosti, doveo subjekt [antropologiju] kroz seriju transformacija, pa ipak [antropologija] suštinski nastavlja da postavlja ista pitanja koja su postavljana pre 50, 100 ili čak 200 godina" (Eriksen i Nielsen 2013: x).

\section{Zaključne napomene: politika pisanja istorije antropologije}

Kao i bilo koja druga ljudska aktivnost, pisati istoriju antropologije nosi sa sobom koristi i rizike. Koristi su, pre svega, mogućnost da autori podele svoje znanje i stavove sa drugima, da sa čitaocima uđu u dijalog kao sa savremenicima, a svakako je velika nagrada za svakog autora/autorku mogućnost da njegova (ili njena) knjiga naiđe na dobru recepciju kod čitalaca. Rizici su da knjiga uopšte ne dođe do onih kojima je namenjena ili da, još gore, bude potpuno pogrešno interpretirana ili ignorisana. Zato je važno razumeti kome je ona namenjena i sa kojim ciljem.

Knjige koje su do sada pomenute u ovom tekstu pisane su sa ciljem da antropologiju približe onima koji se ponekad nazivaju "publikom" (engl. general audience; readership), dok su neke (Barnard, Eriksen i Nielsen) od njih, između ostalog, nastale i sa ciljem da direktno posluže u nastavi antropologije, kao udžbenici. Ponekad je cilj da se predmet o kome se piše malo više osvetli i učini jasnijim i razumljivijim. U knjigama koje se bave određenim delovima sveta (kontinentima ili državama) autorova ili priređivačeva intencija može biti i eksplicitno politička. Primer jednog angažovanog političkog pristupa predstavlja Pattersonova društvena istorija antropologije u SAD-u (Patterson 2001). Iako se radi o veoma zanimljivom i čitljivom tekstu, ovo je primer potencijalne zabune do koje može dovesti naslov knjige. Naime, Patterson je u stvari napisao društvenu istoriju, a ne istoriju antropologije - mada u svom tekstu pominje brojne antropologe (kao i njihovu često problematičnu saradnju sa vlastima i najblaže rečeno "nesnalaženje" tokom određenih političkih kriza). Čitaoci koji očekuju da u njegovoj knjizi pronađu detaljne rasprave o različitim teorijskim pravcima i njihovim međusobnim uticajima ostaće razočarani. Ovde postaje jasno do koje mere su Eriksen i Nielsen bili uspešni u svom poduhvatu budući da je od prikazivanja društvenih okolnosti u kojima određene teorije nastaju vrlo lako skliznuti u "čisti" društveni aktivizam. To, naravno, samo po sebi ne mora biti loše, ali u Pattersonovom slučaju oduzima prostor za raspravu o antropologiji - što je, barem zvanično, bila namera njegove istorije.

Ponekad politička/angažovana autorova intencija nije na prvi pogled očigledna - kao u (inače izuzetno kvalitetnoj) knjizi koju su priredili Ntarangwi, Mills i Babiker (2006). Afričke antropologije se ovde prezentuju u pluralu, što pomaže de-esencijalizaciji određenog koncepta. "Afrika" se - kao egzotika, imaginarij i fantazam - kroz tekstove u ovoj knjizi transformiše u konkretne geografske lokacije, gde, u različitim društvima i kulturama, žive različiti, konkretni ljudi sa svojim željama, brigama, nadama i htenjima. Takođe, kada se radi o specifičnim tradicijama u različitim državama, autori zastupljeni u ovoj knjizi se bave i praktičnim pita- 
njima uloge antropologije u svakodnevnom životu - pre svega kroz problematiku predavanja antropologije, koja je zastupljena u više poglavlja. Ova praktična dimenzija je karakteristična i za relativno skorašnji tekst dvoje portuglaskih antropologa (Viegas e Pina-Cabral 2014), koje zanima kontekst razvoja naše naučne discipline u njihovom (portugalskom) društvenom kontekstu, ali i praktične konsekvence mesta antropologije kao društvene (i humanističke) nauke, kao i budućnosti predavanja antropologije na univerzitetima.

Praktično je neodvojivo od političkog, a političko od istorijskog, pa je tako Hammond-Tooke pre skoro dve decenije napisao sjajnu istoriju antropologije u Južnoj Africi (Hammond-Tooke 1997). Njegova pozicija je bila specifična jer je istodobno bio i učesnik i svedok razvoja discipline u svojoj zemlji. Hammond-Tooke je zaslužan za ustanovljavanje Odeljenja za antropologiju na Rhodes univerzitetu u Grahamstownu, gde je predavao od 1959. do 1970, a nakon toga je bio redovni profesor na Odeljenju za socijalnu antropologiju Univerziteta Witwatersrand, sve do penzionisanja 1991. godine. Ovu relativno kratku studiju o južnoafričkim antropolozima kao "nesavršenim tumačima” je napisao iz ugla istoričara. Kao vremensku granicu svoje analize Hammond-Tooke je stavio 1990. godinu, kada je apartheid kao sistem de facto nestao (sa legalizacijom Afričkog nacionalnog kongresa i južnoafričke Komunističke partije, oslobađanjem Mandele i svih drugih političkih zatvorenika, započinjanjem procesa prenosa vlasti na crnačku većinu u zemlji itd.). Njegova maestralna studija trasira razvoj antropoloških ideja iz različitih tradicija (uostalom, neki od antropologa koje pominje - kao W. W. Max Eiselen sa Univerziteta iz Stellenboscha - imali su odlučujući uticaj na uspostavljanje teorijskih osnova sistema apartheida), ali to čini bez strasti, jasno i precizno. Kao posledica ovakvog (neko bi mogao reći, "racionalnog” ili "objektivnog”) pristupa, Hammond-Tookeova knjiga je od strane nekih njegovih kolega iz anglofone južnoafričke tradicije kritikovana kao "isuviše blaga" u odnosu na njihove kolege iz afrikanerske tradicije. Naravno, sa druge (afrikanerske) strane su ga neki optuživali da je bio previše strog. Ovaj primer pokazuje kako pisanje antropologije može biti nezahvalan posao, barem iz ugla sredine koja je poslužila kao predmet istraživanja - i to posebno u okolnostima za koje bi se moglo reći da su politički osetljive. S druge strane, nesporan $k v a l i t e t$ ove studije predstavlja trajnu vrednost, zbog čega služi kao dokaz da se istorija antropologije koja se bavi potencijalno "škakljivim temama" ipak može napisati.

Da zaključim, idealna istorija antropologije ne postoji, niti će ikada postojati. Najviše čemu se može težiti jesu pojedinačni prikazi, jasno definisani u prostoru i vremenu, uz kritičko korišćenje dostupnih izvora i uz svest o tome za koga se piše i šta se pisanjem jedne kritičke istorije antropologije želi da postigne. Jer, u krajnjoj liniji, uverljivost naših tekstova i jasnoća naših argumenata će zavisiti i od toga kako smo ih napisali.

\section{LITERATURA}

Barnard, Alan. 2011. Povijest i teorija antropologije. Zagreb: Jesenski i Turk.

Bošković, Aleksandar. 2005. "Socio-Cultural Anthropology Today. An Overview". Campos 6/1-2: 11-26.

Bošković, Aleksandar. 2010. Kratak uvod u antropologiju. Zagreb: Jesenski i Turk.

Bošković, Aleksandar. 2014. Antropološke perspektive. Beograd: Institut društvenih nauka.

Bošković, Aleksandar, ur. 2008. Other People's Anthropologies. Ethnographic Practice on the Margins. New York: Berghahn Books.

Bošković, Aleksandar i Chris Hann, ur. 2013. The Anthropological Field on the Margins of Europe, 1945-1991. Zürich: Lit Verlag.

Clifford, James. 1982. Person and Myth. Maurice Leenhardt in the Melanesian World. Berkeley: University of California Press.

Delijež, Rober. 2012. Istorija antropologije. Beograd: Biblioteka XX vek.

Erickson, Paul A. i Liam D. Murphy. 2013. Readings for a History of Anthropological Theory. Toronto: University of Toronto Press.

Eriksen, Thomas Hylland i Finn Sievert Nielsen. 2001. A History of Anthropology. London: Pluto.

Eriksen, Thomas Hylland i Finn Sievert Nielsen. 2013. A History of Anthropology. London: Pluto.

Geertz, Clifford. 1988. Works and Lives. The Anthropologist as Author. Stanford: Stanford University Press. 
Griaule, Marcel. 1948. Dieu d'eau. Entretiens avec Ogotommêli. Paris: Fayard.

Hač, Elvin. 1979. Antropološke teorije. Beograd: BIGZ.

Haddon, Alfred C. i Alison Hingston Quiggin. 1910. History of Anthropology. New York: G. P. Putnam's Sons.

Hahn, Hans Peter. 2013. Ethnologie. Eine Einführung. Berlin: Suhrkamp.

Hammond-Tooke, W. D. 1997. Imperfect Interpreters. South Africa's Anthropologists, 1920-1990. Johannesburg: University of the Witwatersrand Press.

Handler, Richard, ur. 2004. Significant Others. Interpersonal and Professional Commitments in Anthropology. Madison: University of Wisconsin Press.

Hénaff, Marcel. 2000. Claude Lévi-Strauss et l'anthropologie structurale. Paris: Havas.

Johler, Reinhard, Christian Marchetti i Monique Scheer, ur. 2010. Doing Anthropology in Wartime and War Zones. World War I and the Cultural Sciences in Europe. Bielefeld: Transcript Verlag.

Kohl, Karl-Heinz. 1987. Abwehr und Verlangen. Zur Geschichte der Ethnologie. Frankfurt am Main: Ed. Qumran im Campus-Verlag.

Köpping, Klaus-Peter. 2005. Adolf Bastian and the Psychic Unity of Mankind. The Foundations of Anthropology in Nineteenth Century Germany. Münster: Lit Verlag.

Kovačević, Ivan. 2006. "Van Genep po drugi put među Srbima. Prilog istoriji srpske etnologije/antropologije u poslednjoj četvrtini dvadesetog veka”. Etnoantropološki problemi n.s. 1/1: 81-94.

Kovačević, Ivan. 2008. “O pisanju istorije antropologije kraja dvadesetog i početka dvadeset prvog veka”. Antropologija 6: 9-18.

Kovačević, Ivan. 2014. “Dušan Bandić - kontekst, delo, značaj”. Etnoantropološki problemi n.s. 9/1: 17-33.

Kraus, Michael. 2004. Bildungsbürger im Urwald. Die deutsche ethnologische Amazonienforschung; (1884-1929). Marburg: Curupira.

Kuper, Adam. 1998. Antropologija in antropologi. Moderna britanska šola. Šentilj, Maribor: Aristej.

Lowie, Robert H. 1937. The History of Ethnological Theory. New York: Rinehart and Company.

Marett, Robert R. 1912. Anthropology. London: Williams and Norgate, Ltd.

Ntarangwi, Mwenda, David Mills i Mustafa Babiker, ur. 2006. African Anthropologies. History, Critique and Practice. London: Zed Books.

Oberdiek, Ulrich. 2013. Hierarchie und Gehorsam im Fach Ethnologie. Ihr Einfluss auf die Theorieproduktion in Deutschland seit 1950. Münster: Lit Verlag.

Patterson, Thomas C. 2001. A Social History of Anthropology in the United States. Oxford: Berg.

Penniman, T. K. 1965. A Hundred Years of Anthropology. New York: William Morrow and Co.

Petermann, Werner. 2004. Die Geschichte der Ethnologie. Wuppertal: Hammer.

Poarije, Žan. 1999. Istorija etnologije. Beograd: Plato, Biblioteka XX vek.

Stocking, George W. 1995. After Tylor. British Social Anthropology 1888-1951. Madison: University of Wisconsin Press.

Thomas, Nicholas. 1996. Out of Time. History and Evolution in Anthropological Discourse. Ann Arbor: University of Michigan Press.

Viegas, Susana de Matos i João de Pina-Cabral. 2014. "Na encruzilhada portuguesa. A antropologia contemporânea e a sua história". Etnográfica 18/2: 311-332.

Viveiros de Castro, Eduardo. 1999. “Etnologia brasileira”. U O que ler na ciência social brasileira 1970-1995., 1. Sérgio Micelli, ur. São Paulo: Editora Sumaré, 111-223.

\section{Writing History or History of Anthropology as Anthropological Problem}

\section{Summary}

The paper deals with some methodological and practical problems involved in writing and publishing histories of anthropology. A particular emphasis is on the situation with published books dealing with the subject in the former Yugoslavia, especially in Croatia, Serbia and Slovenia. The author then briefly reviews the usefulness of specific anthropological books for the teaching of history of anthropology. A recent revised edition of Eriksen and Nielsen's A History of Anthropology is used as the case study of the book on this topic. The paper concludes with several other relatively recent examples that demonstrate how writing history of anthropology combines practical and political aspects.

Keywords: history of anthropology, politics of anthropology, translations - anthropology, interpretation in anthropology. 